\title{
Sistemas Nacionais de Documentação em Ciência e Tecnologia(*)
}

\author{
LAUNOR F. CARTER
}

$\mathrm{N}$

Ão é de hoje a preocupação com a adequação do sistema de tratamento de documentos e informação dos E.U.A. Desde a Segunda Guerra Mundial já foram apresentadas pelo menos 15 propostas de vulto visando ao estabelecimento de algum tipo de sistema de âmbito nacional. Freqüentemente, os críticos apontam - VINITI ${ }^{1}$, serviço russo centralizado de edição de resumos e divulgação bibliográfica, como o protótipo que bem poderiamos adotar. Dois relatórios recentes, precursores do trabalho que aqui comentamos, mereceram ampla consideração. Em 1962, o "Relatório Crawford" 2, sob o patrocínio do Assessor de Ciência Presidencial, defendia uma grande reformulação das atribuições referentes à informação científica e técnica dos diversos órgãos dentro do govêrno federal. O ano seguinte assinalou o apareci-

(*) Tradução de "National document-handling systems in science and tecnology" publicado em Science 154 (3754); 1299-1304, 9 Dec., 1966. Reproduzido com permissão do autor.

1. VINITi é un acrônimo derivado da transliteração do nome em russo de Instituto de İnformação Cientifica e Técnica de Tôda a União, Vsesoyuznyy Institut Nauchnoy i Tekhnicheskoy Informatsii. Uma descrição dêsse Instituto pode ser encontrada no relatório da SDC citado adiante. Para uma análise crítica russa do VINITI, ver V. S. Malov, Resultados da Verificação to Cumprimento da Resolução do Conselho de Ministros da URSS, «Acêrca de medidas de melhoria da organização da informação cientifica e técnica neste pais», Sci. Tech. Inform. (Selected Articles) ñ 6 (1964), Relatório FTD. MT-65-07, Foreign Technology Division, Air Force Systems Command, Wright-Patterson Air Force Base, Ohio.

2. U.S. Department of Commerce, "Scientific and Technological Communication in the Government" (AD 295 545. Government Printing Office, Washington, 1962). 
mento do "Relatório Weinberg" 3 , sob os auspícios do Comitê Assessor Presidencial para Ciência. Embora cada um dêsses relatórios tivesse merecido, por parte do govêrno, atenção de alto nivel, suas recomendações não foram amplamente adotadas. Mais exatamente, algumas de suas partes foram incorporadas na estrutura existente. Uma inovação foi a formação do Committee on Scientific and Technical Information (COSATI) do Federai Council for Science and Technology. O Diretor do Office of Science and Technology solicitou ao COSATI que empreendesse um amplo estudo que levasse à formulação de recomendações visando a um sistema nacional de tratamento de documentos em ciência e tecnologia. Os resultados do estudo do COSATI, feito com a colaboração de uma equipe da System Development Cor poration (SDC), estão contidos num extenso relatório ${ }^{4}$, cujos pontos principais são aqui passados em revista.

\section{O PROBIEMA}

Cada um dos trabalhos acima mencionados encara os problemas relativos ao tratamento das informações e documentos científicos e técnicos de um ponto-de-vista um tanto diferente, principalmente porque não foram abordados como um único problema de múltiplas facêtas. Há muitos problemas diferentes que, quando somados, indicam que as práticas e as instituições em curso necessitam de uma revisão de vulto. Entre os problemas que têm de ser considerados por um projeto amplo encontram-se os seguintes:

1) Deve-se esclarecer e formalizar a responsabilidade federal pela documentação cientifica e técnica. Afirma-se, como uma proposição básica, que o govêrno federal deve ter o encargo de garantir a existência nos Estados Unidos de pelo menos uma cópia acessivel de cada publicação significativa da literatura cien tífica e técnica do mundo inteiro. Até agora isso não tinha sido explicitamente aceito como um encargo do govêrno federal. Con: eqüentemente, muitas repartições do govêrno não se acham vol-

3. Comitê Assessor Presidencial para Ciências, "Science, Government, and Information: The Responsabilities of the Technical Community and the Go-
vernment in the vernment in the Transfer of Information" (The White House, Washington,
jan. 1963). 4. L. F. Carter, G. Cantley, J. T. Rowell, L. Schultz, H. R. Seiden,
E. Wallace, R. Watson, R. E. Wyllys, "Recommendations for National
Document Handling Systems in Science and 213/001/00. Handling Systems in Science and Technology" (TM-WD1965. Disponivel como PB 168.267 na Clon, Santa Monica, Calif., Sept. and Technical Information). 
tadas para a execução de tal política, nem poderiam fazê-lo com a devida presteza se essa politica fôsse formalmente adotada.

2) O número de usuários e suas exigências cresce progres sivamente. Em 1960, havia 2.370.000 cientistas, engenheiros e técnicos nos Estados Unidos; calcula-se que haverá 4.000.00n até $1970^{5}$. As necessidades de documentação dêsse pessoal diferem substancialmente, segundo o trabalho que realizam. Cientistas e estudiosos pedem um tipo de serviço, engenheiros, um tipo diferente, e os responsáveis pelas tarefas técnicas, um terceiro tipo. O sistema atual de informação e documentação de bibliotecas e centros de informação não atende adequadamente às necessidades atuais e estará cada vez menos apto a enfrentar um grande aumento das exigências dos usuários.

3) A quantidade de publicações cresce continuamente; de fato, dobra cada 15 anos. Uma estimativa coloca o número de documentos técnicos publicados em 1961 na casa dos 658.000 e o número a ser publicado em 1970 na casa de 1.143.000. Ė̀m 1964 a Biblioteca do Congresso possuia mais de 43.000 .000 de itens em sua coleção. Isso representa um aumento de mais de $180 \%$ nos últimos 26 anos. À proporção que aumenta a quantidade de documentos, torna-se cada vez mais dificil às bibliotecas de pesquisa arrostar os problemas de aquisição, catalogação, indexação, divulgação bibliográfica, circulação e armazenagem dêsses documentos. As bibliotecas reagem a êsses problemas tornando-se mais especializadas, restringindo sua clientela ou reduzindo seus serviços. É claro que se faz necessário um sistema racionalizado para tratar a quantidade crescente de documentos ${ }^{6}$.

1) No sistema atual torna-se difícil às bibliotecas e centros de documentação prestar serviços de alta qualidade. É difícil dar números exatos em apoio desta afirmativa, mas muitos indícios separados levam a essa conclusão.

Em 1965, por exemplo, o Congresso aprovou uma verba especial de 5 milhões de dólares para a Biblioteca do Congresso. Parte dessa quantia será usada para financiar um trabalho acelerado de catalogação. As fichas de catálogo da Biblioteca do

5. L. J. Carter, Science 151: 666, 1966.

6. Freqüentemente se sugere que muito de valor duvidoso é publicado e que se deveria adotar medidas a fim de reduzir o volume do que é publicado. É fácil concordar neste ponto mas muito dificil imaginar métodos que reduzam a quantidade de material nôvo. Os melhores periódicos têm um a'to indice de rejeição de originais e continuamente surgem novos periódicos. Os relatórios periòdicamente encomendados pelo govêrno complicam ainda mais o problema. Um dos primeiros esforços da Agência de Supervisão, da qual falaremos adiante, deveria ser um ataque a êste problema. 
Congresso são usadas por tôdas as bibliotecas da nação, mas o atraso de sua publicaçao está-se tornando grave e elas estão fazendo a cobertura de uma proporção menor da quantidade total de documentos.

$O$ fato de muitos mecanismos novos para intercâmbio de informações estarem sendo adotados indica que os meios tradicio nais de comunicação são inadequados. Grande número de viagens entre um e outro centro, publicações informais, amplo uso de pré-publicações e simpósios restritos suplementam os métodos de comunicação mais antigos e mais públicos.

Algumas bibliotecas possuem um grande acúmulo de livros e outros documentos que não podem ser processados e incluídos no acervo, e se acham também limitando seus serviços. Por exemplo, um número cada vez maior de bibliotecas universitárias vem reduzindo seus serviços a organizações industriais vizinhas, devido à falta de recursos adequados na biblioteca.

Trabalhos feitos por usuários de bibliotecas demonstram uma significativa insatisfação com o sistema atual e, ao mesmo tempo, uma séria carência de informações sôbre como usar o sistema. O usuário volta-se para outras fontes ou não usa os sistemas de informação e bibliotecas na medida em que deveria fazê-lo.

O número de pessoas que são atraídas e formadas em biblioteconomia está muito aquém da demanda, e a média de crescimento neste setor é menor do que a da fôrça de trabalho profissional geral.

A situação orçamentária da maioria das bibliotecas de pesquisa privada é critica. As grandes fundações privadas e os filantropos já não mais amparam o funcionamento das bibliotecas e os recursos municipais são escassos.

De uma maneira descoordenada, muitas das partes do sistema de informação e documentação estão na dependência de apoio federal. Subsidios diretos, pagamentos pela publicação de artigos, auxílios especiais, autorizações gerais, acôrdos de trabalho especiais e contratos, tudo depende do govêrno federal.

5) As inovações tecnológicas não têm sido utilizadas pelas bibliotecas, que, com poucas exceções, empregam virtualmente as mesmas técnicas manuais de há 50 anos atrás. Para esta situação existem três causas fundamentais. A maioria dos bibliotecários e as tradições da Biblioteconomia baseiam -se mais nas humanidades do que na tecnologia. Conseqüentemente, muitos dos responsáveis pela formulação da política a ser seguida pelas bibliotecas respectivas tendem a hesitar diante dos potenciais da tecnologia 
moderna. Outra causa disso é a relativa pobreza das bibliotecas. Comumente, as bibliotecas mal podem arcar com seu funciona mento de rotina, quanto mais experimentar técnicas novas. A terceira causa é que as técnicas automatizadas ainda não foram desenvolvidas para uma adaptação fácil a muitas bibliotecas. $O$ custo da adaptação de tecnologia avançada para os problemas dos centros de documentação e informação será elevado. Por enquanto, os esforços do govêrno federal neste sentido têm sido modestos, mas, se tivermos de fazer face ao número crescente de usuários e documentos, ter-se-á de desenvolver e aplicar novas técnicas.

6) Há necessidade de um planejamento a longo prazo. O sistema atual compõe-se de muitas unidades independentes: no govêrno, em universidades, em associações profissionais, como esforços privados, e na indústria. Cada uma dessas unidades segue seu rumo separado em têrmos de planos e recursos. Cada uma percebe seus problemas individuais, mas podem ou não ter ciência do problema nacional maior (inclusive problemas de coincidência parcial de coleções, catalogação duplicada, serviço inadequado para certos grupos de usuários, e assim por diante). Não existe um plano nacional de longo alcance ou um órgão de planejamento que possibilite a coesão dêsses esforços isolados. Antigamente, grupos de estudo ad hoc ou funcionários do govêrno, individualmente, elaboraram planos ou sugeriram solıções para os problemas, mas êsses esforços não levaram a qualquer ação sisteriática. Com freqüência, soluções parciais - como o estabelecir mento da National Library of Medicine e o serviço MEDLARS que ela proporciona - representam o êxito de um grupo particular de usuários. No entanto, à medida que as pressões do número crescente de usuários, do número crescente de documentos e do potencial crescente da tecnologia avançada continuam a avolumar-se, torna-se manifesta a necessidade de um planeja mento de longo alcance ${ }^{7}$.

\section{MÉTODO DE ESTUDO DO PROBLEMA}

O critério inicialmente adotado no estudo patrocinado pelo COSATI foi seguir três linhas de esfôrço, separadas mas relacionadas. Como medida inicial passaram-se em revista os estudos

7. Em setembro, o Presidente Johnson nomeou uma National Advisory Commission on Libraries, a fim de "fazer uma avaliaçăo das politicas, prugramas e práticas dos órgãos públicos e das organizações privadas, e recomendar medidas que devam ser tomadas por grupos públicos e privados visando a assegurar um sistema efetivo e eficiente de bibliotecas para a nação." 
e as propostas anteriores. Foram reunidos e analisados estudos feitos pelo Congresso, relatórios do Comitê Assessor Presidencial para Ciência, relatórios de outras fontes do govêrno e estudos de fontes privadas. Uma segunda área de pesquisa ficou centralizada em tôrno dos estudos das necessidades dos usuários relativas à informação técnica e científica. Embora tivessem sido identificados 450 dêsses estudos, a equipe de trabalho da SDC concentrou-se em 58 que pareciam estar baseados em dados empíricos significativos, a fim de ter uma compreensão das opiniões dos próprios usuários a respeito de suas necessidades. $O$ terceiro $€$ ma1s extenso esfôrço foi devotado a compreender o atual sistema de informação cientifica e técnica. Foram visitadas 47 do grande número de instituições do govêrno federal e no setor não-federal que prestam serviços de informação científica e técnica. Ademais, revisaram-se as bases legislativas da existência dêsses serviços 6 coletaram-se dados estatísticos em grande número.

Em decorrência dêsses estudos ${ }^{8}$ formulou-se uma série de proposições básicas e necessidades do sistema. A medida que os estudos iam progredindo e as necessidades iam sendo definidas, a equipe considerava e desenvolvia idéias para diversos sistemas alternativos que parecessem capazes de atender uma importante parcela dos requisitos e que tivessem alguma possibilidade prática de serem postos em execução. Elaboraram-se seis planos alternativos que foram arquitetados com minúcia considerável. Os planos foram elaborados a partir de várias fontes, inclusive propostas anteriores. Provàvelmente, nenhuma concepção do presente trabalho é completamente original, entretanto, as características enumeradas, mais a discriminação dos detalhes de concepção e implantação, são $u$ m produto impar dêste estudo.

\section{PROPOSIÇÕES E REQUISITOS BÁSICOS}

Além do encargo do govêrno federal de garantir que pelo menos uma cópia de tôda publicação cientifica e técnica importante possa ser encontrada nos Estados Unidos, os princípios mais importantes estabelecidos foram os de que o govêrno federal seja responsável pela garantia de que essas publicações, uma vez adquiridas, sejam convenientemente anunciadas, processadas e

8. L.F. Carter et al. (4, vol. 2, 404 p.) indicam os resultados detathados dêsses estudos. Ademais, descrevem-se diversos sistemas tecnològicamente avançados e tecem-se comentários sôbre a capacidade presente e provável de futuro imediato dos componentes técnicos necessários para grandes sistemas automatizados. 
postas à disposição de pessoas qualificadas dentro dos Estados Unidos, e de que os sistemas propostos devem ser evolucionários, no sentido de que devem começar com os sistemas atuais (bibliotecas, intercâmbio de informações, etc.) e evoluir para formas que sejam consentâneas com um plano geral. Deve haver flexibilidade que permita novas providências de organização e administração.

Embora cada princípio precise ser discutido, um desenvolvimento da primeira e mais fundamental proposição proporcionará uma avaliação da importância dessas afirmações básicas. O conceito de encargo federal de garantir a disponibilidade de tôdas as publicações cientificas e técnicas significativas contém diversas idéias que precisam ser definidas ou qualificadas.

Como determinar que uma publicação é ou não é significativa?. Antes de tudo deve-se dispor de um documento ou um bom resumo a partir dos quais se possa fazer um julgamento. Se um documento não é encontrado nos Estados Unidos, então o julgamento deve ser feito alhures, provàvelmente, por especialistas no país de origem. Além do mais, não se pode fazer uma avaliação de significado em têrmos de percepção atual da possível relevância, uma vez que essa relevância está sujeita a mudanças periódicas. Antes, a importância precisa ser julgada em têrmos da correção e do caráter profissional do trabalho relatado. A longo prazo o sistema deve aspirar a que todo documento publicado disponível nos Estados Unidos seja avaliado por especialistas apropriados norte-americanos. Como esfôrço mínimo desejaríamos incluir tôdas as publicações seriadas, documentos de serviços de monografias reconhecidos e livros de editôres reconheciclos. Relatórios e folhetos ocasionais seriam os últimos a serem incluídos. A presteza com que se possa atingir essa meta dependerá da importância que lhe conceder a comunidade científica em comparação com metas concorrentes e da disposição do Congresso em proporcionar os recursos necessários. (Talvez estejamos mais perto dessa meta do que se imagina. O acervo de literatura de livre consulta das agências de informação estratégicas é imenso. Fugia ao âmbito do estudo da SDC fazer uma pesquisa, mas deve-se fazê-la a fim de conhecer em que limite os acervos não confidenciais dessas agências poderiam ser postos à disposição da comunidade civil).

O "encargo" atribuído ao govêrno federal implica em que um sistema da administração federal saberá o que existe nos Estados Unidos, não apenas nos depósitos oficiais, mas também nas bi- 
bliotecas privadas e universitárias. Em outras palavras, deve existir um catálogo coletivo nacional e um índice dos acervos de documentos das mais importantes bibliotecas. Isso será uma emprêsa de vulto.

O conceito de acessibilidade também precisa ser desenvolvido. Implica em que qualquer documento pode ser obtido de uma maneira eficiente e a tempo por parte de uma classe de usuários ainda por ser definida.

O que se quer dizer com literatura "científica e técnica"? Não há desacôrdo quanto à inclusão de Astronomia, Matemática, Física, Química e Biologia. Mas, e quanto às ciências sociais e psicológicas? O sistema deve incluir essas disciplinas devido a sua crescente importância nacional e seus rápidos progressos. Ein cutras palavras, Psicologia, Sociologia, Antropologia Cultural, Ciência Politica e Economia incluem-se na definição de ciência e tecnologia. Até onde chegaremos em áreas como Engenharia Industrial, Tecnologia de Manufaturas e Engenharia Administra. tiva? O sistema deve incluir essas áreas. Seu objetivo é cobrir ein sentido lato a ciência e a tecnologia.

O número de critérios bàsicamente diferentes com que se pode tratar o problema da informação documentária é bem limitado. A equipe da SDC considerou quatro critérios (embora haja três variações em uma idéia). Um dêles acentua a necessidade de uma organização de integração e planejamento (Agência de Supervisão) que formule e implante a politica nacional e federal; outro dá ênfase ao estabelecimento de atribuições definidas para os diversos departamentos e agências federais; o terceiro diz respeito à centralização de todos os encargos de funcionamento em uma grande organizaçâo federal ou privada, e o quarto retrata a lenta evolução do sistema existente. A todos quatro podem-se dar diversas interpretações e ênfases e podem ser considerados em várias combinações.

\section{A AGÊNCIA DE SUPERVISÃO} A Agência de Supervisão seria uma nova repartição no
Setor Executivo do govêrno e gozaria de uma autoridade geral
de orientação e revisão de orientação e revisão referente à informação e documentação cientifica e técnica. A Agência de Supervisão proposta, denominada Scientific and Technical Information Bureau, não seria uma nistração operacional, mas, antes, uma agência de direção ou administração geral que se ocuparia das atividades de informação e documentação nos vários departamentos e repartiçóes do govêrno 
federal e grupos externos relacionados. O Bureau formularia uma política e seria responsável pelas funções abaixo discriminadas:

Existem atualmente diversas bibliotecas nacionais e se indica que diversos outros sistemas nacionais devem ser criados. $O$ Bureau determinaria quais os que serão cobertos por quais departamentos e repartições, e deveria definir as atribuições dos vários departamentos e repartições.

O Bureau deveria estabelecer uma politica federal referente ao apoio e cooperação com as bibliotecas não-governamentais. À medida que o programa federal de informação e documentação tornar se desenvolvido e padronizado, acabará por afetar as bibliotecas não-governamentais. Algumas repartições federais podem delegar parte de suas atribuições a bibliotecas ou organizações fora do govêrno. Na medida em que as grandes bibliotecas universitárias ou bibliotecas privadas apoiarem ou financiarem os empreendimentos federais, elas deverão ser financiadas com recursos federais.

Em todo o país existem cêrca de 300 centros importantes de informação em ciência e tecnologia. Alguns dêles são financiados pelo govêrno federal, alguns são da indústria privada e outros das universidades. O funcionamento e os serviços por êles prestados variam consideràvelmente, o que era de se esperar, mas essa variação não está de acôrdo com qualquer plano ou critério sistemático para centros de informação. Precisa-se formular uma política relativa à ajuda e patrocinio de centros de informação, o que seria uma função do Bureau.

Presentemente há mais de 1.200 bibliotecas em todo o país que são depositárias de documentos oficiais. A extensão de suas receitas e acervos varia consideràvelmente. Há necessidade de desenvolver-se uma política referente à distribuição, processamento c ajuda a êsses depósitos.

No momento adotam-se muitas práticas no que toca às publicações científicas e técnicas não-oficiais. No campo das publicações primárias existe alguma subvenção direta; com freqüência faz-se o pagamento pela publicação de artigos através de contratos de pesquisa. De modo similar, entre as publicações secundárias, algumas publicações de resumos recebem um subsidio muito substancial, enquanto outros serviços de resumos nada recebem. Os padrões de diretrizes e financiamento nesta área carecem de racionalização. 
Um método primário de comunicação, tanto formal como informal, entre os cientistas, é através do método não-documentario de cartas, visitas, pequenas reuniões, simpósios, reuniões nacionais, etc. A politica federal relativa a essas atividades varia. Tôda a área de comunicações não-documentárias precisa ser estudada extensamente, e a politica desenvolvida e implantada.

As estatísticas correntes acêrca do tamanho de coleções, consultas, orçamentos etc. muitas vêzes não são obteniveis ou são incompletas e são raramente comparáveis entre uma e outra atividade. Deve-se desenvolver uma informação estatística de confiança em tôda a área de documentação e informação científica e técnica.

O Bureau deveria estabelecer normas para o tratamento da informação a serem seguidas por tôdas as organizações federais que fôssem incumbidas da informação e documentação em ciência e tecnologia. Os padrões de execução dizem respeito a matérias como integridade de cobertura, velocidade de serviço e natureza e qualidade dos serviços prestados aos usuários. As normas técnicas aplicam-se a áreas como catalogação, classificação, bibliografias, microarmazenagem e automatização.

Atualmente a National Science Foundation tem uma atribuição importante tanto em pesquisa sôbre ciência da informação como em várias atividades de informação científica. A criação do Bureau mudaria essa situação no que se refere à informação científica. No entanto, antecipa-se que a pesquisa básica em ciência da informação permaneceria sendo atribuição da NSF e desfrutaria da mesma condição de qualquer das outras áreas importantes da pesquisa científica.

Para o desenvolvimento de uma tecnologia avánçada para tratamento de documento há necessidade de uma ampla orientação e estímulo. O Bureau teria um papel ativo no estímulo à aplicação da tecnologia avançada e das técnicas de automatização nas bibliotecas do govêrno e em outros centros de informação.

Existe uma carência de tecnologistas de informação e de bibliotecários treinados em ciência e tecnologia, e a situação não melhorará no nivel atual de interêsse e apoio. É preciso formular uma política federal referente ao amparo, ao treinamento do pessoal necessário, bem como proporcionar recursos financeiros des-
tinados a treinamento. Há muito mais publicações seriadas e documentos estran-
geiros do que nacionais, embora $60 \%$ de todos os documentos
sejam publicados em ingle sejam publicados em inglês. É necessário estudar extensamente 
e adotar uma política para a aquisição e tradução dos documendos estrangeiros.

Muitos dos cientistas e estrangeiros não são informados sôbre os serviços disponíveis. O Bureau deveria dar publicidade às fontes de informação e aos serviços e também ajudar no treinamento dos usuários com a finalidade de poderem usar com eficiência os serviços existentes.

A informação e documentação em ciência e tecnologia representam uma vultosa despesa federal, da ordem de 200 milhões de dólares em gastos diretos por ano. (Algumas estimativas indicam êsse número como sendo de cêrca de 400 milhões de dólares). Além da inspeção normal pelo Departamento do Orçamento, deveria haver uma inspeção total dos recursos para as atividades de informação e documentação.

Como o órgão responsável pelo programa nacional de infor mação e documentação, o Bureau deveria analisar tôdas as propostas legislativas relevantes apresentadas pelo govêrno. Deveria também formular propostas nos pontos que dissessem respeito às diretivas nacionais.

O desenvolvimento da ciência e da tecnologia e a crescente demanda de serviços indicam a necessidade de um planejamentı duradouro. O Bureau seria o responsável pela elaboração de pla nos de longo alcance.

Além de considerar as funções que precisam ser realizadas, o estudo do COSATI discrimina detalhadamente uma sugestão para organização do Scientific and Technical Information Bureau. Indicam-se quatro principais divisões estruturais: um Serviço de Sistemas, um Serviço de Apoio e Diretivas Externas, um Serviço de Métodos e Aplicações Técnicas e um Serviço de Planos.

Finalmente, a localização do Bureau precisa ser considerada. Essas atividades, de preferência, seriam realizadas em uma das repartições já existentes, mas, após estudar os argumentos pró e contra a atribuição de seu encargo ao Office of Science and Technology, National Science Foundation, Bureu of the Budget e General Services Administration, concluiu-se que era preciso uma nova organização no setor de Independent Offices and Establishments do Poder Executivo. No caso de o OST ou a NSF virem a ter suas atribuições ampliadas e seus quadros aumentados, dever-se-ia reconsiderar a recomendação referente à subordinação. O ponto importante é que as várias funções enumeradas precisam ser levadas a cabo. Se é preciso uma nova agência, ou se as atribuições das que já existem podem ser convenientemente 
expandidas é uma questão que tem de ser examinada por aquêles que estejam mais familiarizados com o plano de organização geral do Poder Executivo.

\section{O SISTEMA DE REPARTIÇÃO RESPONSÁVEL}

De acôrdo com o Sistema de Repartição Responsável, uma autoridade competente designaria uma organização específica como a entidade responsável pela manutenção de realização satisfatória de tödas as tarefas necessárias para proporcionar serviços de informação num setor definido do amplo aspecto da ciência e tenologia. A organização necessàriamente não realizaria ela mesma tôdas essas tarefas, mas garantiria que as mesmas seriam executadas, se não por si, mas por organizações outras no govêrno ou no setor não-federal.

O conceito de Repartição Responsável surgiu como uma su. gestão do Relatório Weinberg que indicava as funções de informação que estava sendo executadas pela Atomic Energy Commission e pela National Aeronautics and Space Administration em seus respectivos campos. No entanto, não se fêz uma análise minuciosa da aplicabilidade da idéia a outras áreas, não chegando a se concretizar o apnio e a implantação da mesma. No estudo feito pela SDC considera-se em profundidade a aplicabilidade do conceito em relação com as metas nacionais, atribuições de repartições oficiais e agrupamentos razoáveis de áreas científicas e técnicas.

O sistema recomendado pela equipe de estudo da SDC foi uma combinação da Agência de Supervisão com o conceito de Repartição Responsável. Contudo, a equipe deu atenção a diversos sistemas alternativos ao ponto de analisar o conceito geral, desenvolver um esquema de operações, indicar uma possivel organização, definir funções a serem executadas e desenvolver os argumentos a favor e contra cada uma dessas alternativas. Essas alternativas foram as seguintes:

1) Uma nova Repartição Administrativa Federal. Uma nova repartição federal poderia ser criada com a finalidade de assumir inteiramente o encargo pela informação e documentação. Êsse nôvo órgão não seria sòmente responsável pela politica, mas também faria funcionar um serviço nacional.

2) Uma Emprêsa licenciada pelo Govêrno. Muitas das funções e atividades a serem realizadas pela Nova Repartição Administrativa também podem ser executadas por uma emprêsa privada especial licenciada pelo govêrno. 
3) Uma Administração Nacional de Bibliotecas no Poder Executivo. Seria possivel fundir as principais bibliotecas atualmente existentes no govêrno federal. Devido às vultosas coleções e ao estado especial da Biblioteca do Congresso o problema de informação e documentação científica e técnica poderia ser solucionado com a transferência da Biblioteca para o Poder Executivo e a ampliação e reformulação das áreas de operações e atribuiçc̃es dela e de outras grandes bibliotecas e serviços de informação.

4) Fortalecimento do Sistema Existente. Pode-se alegar que um serviço um tanto adequado está atualmente sendo prestado e que o sistema atual deveria permitir-se que evoluísse tanto quanto no passado. O Office of Science and Technology poderia ser fortalecido e se poderiam formar pequenos grupos de orientação em outras repartições existentes a fim de realizar certa coordenação suplementar.

\section{AVALIAÇÕES}

Depois que cada uma das alternativas foi descrita, cada uma foi avaliada em têrmos de 43 exigências de projeto elaboradas anteriormente. Embora o sistema de Agência de SupervisãoRepartição Responsável estivesse à frente na avaliação, não foi acentuadamente superior à Nova Repartição Administrativa, Emprêsa Licenciada pelo Govêrno ou Administração Nacional de Bibliotecas, pelo menos no que toca a consideraçôes técnicas. A avaliação concluiu afirmando que:

"Os conceitos da Nova Repartição Administrativa e da Administração Nacional de Bibliotecas envolvem mudanças radicais no funcionamento e na administração que não são consoantes com nossa concepção da necessidade de um desenvolvimento evolucionário. Por enquanto, são inaquedadas as bases pelas quais se poderia chegar a especificações detalhadas para um sistema de operações centralizado. Ademais, o conceito de Administração Nacional de Bibliotecas exige a transferência da Biblioteca do Congresso para o Poder Executivo, o que provàvelmente seria difícil do ponto-de-vista político. Ambos os conceitos implicam ern extensas transferências de atribuições e contrôle central de serviços de tratamento de documentos."

A Emprêsa Licenciada pelo Govêrno é uma alternativa atraente, devido a seus pontos de contacto com o setor nãofederal, mas tem a anuladora debilidade de invadiu profundamente apenas atividades federais. 
Não se recomendou a opção de simplesmente fortalecer o sistema atual, baseando-se em que não estava atualmente satisfazendo muitas das necessidades do momento e não parecia grande a probabilidade de que viesse a satisfazê-las no futuro.

O projeto recomendado - a combinação da Agência de Supervisão com a Repartição Responsável - é evolucionária e representa a melhor solução para atender as necessidades. Além do mais, de todos os projetos considerados, êste proporciona o máximo grau de flexibilidade para adaptação às necessidades em mudança. Enfim, como requer o minimo de mudança no funcionamento existente, seria a solução mais aceitável para as organizações atualmente incumbidas de tratar os documentos e informações científicos e técnicos.

\section{AS RECOMENDAÇÕES DO COMITÊ}

O estudo da SDC serviu como material básico para o Grupo de Trabalho sôbre Sistemas Nacionais do COSATI. As recomendações do Grupo de Trabalho foram endossadas pelo COSATI, sob a presidência de William T. Knox do Office of Science and Technology, que posteriormente apresentou-as ao Federal Council for Science and Technology. O relatório do $\operatorname{COSATI}^{9}$ recomenda que:

1) O Office of Science and Technology deve acelerar seus esforços no planejamento geral, formulação de politica, organização, coordenação e avaliação da rêde nacional integrada de sistemas de informação e documentação em ciência e tecnologia, e deve tomar as medidas adequadas para tornar claras as áreas de responsabilidade entre as repartições federais pertinentes.

2) O Office of Science and Technology, em colaboração com o Bureau of the Budeget, departamentos federais, repartições e outras organizações ligadas à ciência e tecnologia, deve imediatamente tratar de: (i) desenvolver um programa amplo e coordenado para garantir a aquisição, catalogação e divulgação da literatura científica e técnica significativa; (ii) elaborar políticas relativas às bases legais para serviços de documentação e informação em ou patrocinados pelos departamentos e repartições, e (iii) propor ou endossar a legislação que possibilite aos departamentos e repartições assumirem o encargo de garantir serviços 9. Federal Council for Science and Technology, "Recommendations for
National Document Handling Systems in Science and Technology" (Nov. 1965.
Disponivel como PB 168267 Technical Information, Springf na Clearinghouse for Federal Scientif:c and 
cficientes de informação e documentação em áreas determinadas de ciência e tecnologia. Deve-se considerar, como elementos da rêde nacional integrada, o estabelecimento de uma ou mais bibliotecas nacionais nos campos da ciência e tecnologia além de Medicina e Agricultura.

3) O Office of Science and Technology, em colaboração com os órgãos federais competentes, deve estimular o setor privado a que formule planos e programas de tratamento de documentos e os documentos e os apresente à sua consideração (e para análise por parte dos órgãos apropriados) visando ao desenvolvimento da rêde nacional integrada.

4) Committee on Scientific and Technical Information deve recomendar que se tomem medidas visando ao desenvolvimento de um plano e critérios coordenados de apoio federal a experiências em tecnologia da informação, inclusive sistemas protótipos de informação planejados com o fim de proporcionar dados de planejamento para a rêde nacional integrada.

As tarefas permanentes de alta prioridade incluem o desenvolvimento de métodos normalizados de processamento de documentos de modo que o intercâmbio entre as diversas entidades. possa ser mais amplo e mais eficiente, a elaboração de diretrizes para análises e contrôle de despesas e orçamento por parte das repartições de seus serviços de documentação e informação, o desenvolvimento de currículos de formação e treinamento para os funcionários e usuários dos sistemas de documentação e informação, e o desenvolvimento de diretrizes para aquisição, disseminação e tradução de documentos estrangeiros não confidenciais em ciência e tecnologia e para a disseminação de informações e dados produzidos no âmbito federal para países e organizações estrangeiros.

\section{RESUMO}

Em decorrência dos estudos aqui descritos e das recomendações do COSATI, como também de consultas e discussões em muitos níveis do govêrno e com organizações profissionais e industriais, o Office of Science and Technology tem um esquema para ação e apoio para promover o aperfeiçoamento do tratamento dos documentos científicos e técnicos.

Launor F. CARter - Vice-presidente sênior da System Development Corporation, Santa Mônica, Califórnia, E.U.A. - Tradução de Antônio Agenor Briquet de Lemos (Da Universidade Nacional de Brasilia). 